\title{
O pensamento sem dissimulação
}

\section{Thought without dissimulation}

EFEMÉRIDE

Jean Baudrillard (Reims, 1929 - Paris, 2007)

Autor

Juremir Machado da Silva

Doutor em Sociologia pela Universidade Paris-Descartes Sorbonne. Professor do Programa de Pós-Graduação em Comunicação Social da PUCRS.

<juremir@pucrs.br>

\section{RESUMO}

Este artigo inventaria a trajetória de Jean Baudrillard, pensador francês que faleceu em 2007 deixando uma obra provocativa, contundente e original na fronteira entre filosofia, sociologia, antropologia e comunicação.

Palavras-chave: Baudrillard. Filosofia da Comunicação. Mídia.

\begin{abstract}
This article would invent the trajectory of Jean Baudrillard, a French thinker who died in 2007 leaving a provocative, forceful and original work on the frontier between philosophy, sociology, anthropology and communication.
\end{abstract}

Keywords: Baudrillard. Philosophy of communication. Media.

“De toute façon, s'il veut parler d'illusion, le langage doit se faire lui-même illusion.

S'il veut parler de séduction, il doit se faire séduction."

"S'il n'y avait pas les apparences, le monde serait un crime parfait, c'est-à-dire sans criminel, sans victime et sans mobile."

Jean Baudrillard

O crime perfeito não aconteceu. A realidade fez a sua reaparição. Se não houve móbil nem criminoso, salvo a doença ou a natureza, a vítima era bem conhecida. O sociólogo, filósofo, poeta e fotógrafo Jean Baudrillard morreu em 6 de março de 2007. Morte natural. Mais um paradoxo na sua existência feita de antagonismos. O grande pensador francês - certamente o maior dos últimos 50 anos na capacidade de aliar originalidade de ideias e exuberância de estilo - havia denunciado num livro desconcertante as impossibilidades de 
um ponto final (L'illusion de la fin ou la greve des événements, 1992). A vida não tem fim, ele costumava dizer, com o seu sorriso irônico. Os homens é que teriam inventado (ou simulado) sentidos, finalidades e até mesmo a passagem do tempo como uma absurda ruptura. Baudrillard morreu há dez anos.

Em La transparence du mal - essai sur les phénomènes extrêmes, ele foi ainda mais longe na sua especulação:

\begin{abstract}
Rien (ni même Dieu) ne disparaît plus par la fin ou la mort, mais par prolifération, contamination, saturation et transparence, exténuation et extermination, par épidemie de simulation, transfert dans l'existence seconde de la simulation. Plus de mode fatal de disparition, mais un mode fractal de dispersion (Paris, Galilée, 1990, p. 12).
\end{abstract}

Se Baudrillard tiver desaparecido no cosmos certamente não será por banalização ou por extinção, mas por excesso de lucidez e de pertinência numa dispersão fractal de ideias paradoxais, hiperbólicas, viróticas, translógicas e vivas. Nascido em Reims, em 20 de julho de 1929, Jean Baudrillard foi primeiro germanista e crítico literário. Começou ensinando no ensino médio. Em 1966, defendeu a tese O sistema dos objetos (publicada dois anos depois pela Gallimard), sob a orientação de Henri Lefebvre. Em 1972, tornou-se professor na Universidade de Nanterre (Paris X).

Em 1986, passou a integrar o Institut de recherche et d'information sócioéconomique de Paris IX (Dauphine). A sua carreira de pensador teve várias fases. Inicialmente, influenciado pelo estruturalismo e por pensadores como Guy Debord, Henri Lefebvre e Roland Barthes, situou-se como um neomarxista em busca de uma renovação teórica e de um suplemento de utopia para um mundo em crise de referências. É o tempo, entre outros, do já citado O sistema dos objetos (1968), de La société de consommation (1970), de Pour une critique de l'économie politique du signe (1972) e de um livro de grande impacto: Le miroir de la production (1973).

Numa segunda fase, Jean Baudrillard ganha em originalidade e afasta-se da sua matriz de pensamento. É a época de Echange symbolique et la mort (1976), L'effet Beaubourg, OublierFoucault (1977) e Dela Séduction (1979). Mas é na terceira fase, inaugurada em 1981 com Simulacres et simulation, que aparecerá em todo o esplendor o polemista, o paroxista, o provocador e especialmente o rei dos paradoxos. Baudrillard evolui da crítica à ironia, da utopia renovada ao niilismo cáustico e da tática frontal às estratégias fatais. O ensaio argumentativo cederia lugar cada vez mais ao fragmento (como se verá mais tarde nos cinco volumes 
de Cool mémories), aos aforismos, à frase chocante e às fórmulas deliciosamente impiedosas. Até o fim essa capacidade seria aguçada e aperfeiçoada, o que pode ser visto em Power inferno (2002), reunião de artigos sobre os ataques terroristas de 11 de setembro de 2001 nos EUA.

Em todo o seu percurso, Baudrillard foi um mestre das imagens, das analogias e dos recursos linguísticos para compreender o vivido. Ele fez do termo "metástase" uma metáfora devastadora para explicar os processos de decomposição do tecido social contemporâneo. Tudo desapareceria realmente por saturação, disseminação patológica, difusão virótica, proliferação excessiva e caótica, banalização, hiper-exposição, visibilidade exagerada e doentia. $\mathrm{O}$ excesso de luz faz desaparecer uma imagem. Paradoxalmente, outra vez um paradoxo no seu caminho de brilhantes excessos, foi um câncer que o matou. Paradoxo ou redundância? Ironia ou excesso de realidade? Liberação final e total da energia ou puro esgotamento? Baudrillard deixou a vida para continuar definitivamente nas ideias e nas páginas, onde já se encontrava provisoriamente desde a sua primeira incursão na análise dos objetos e na arte da geração de novas hipóteses.

Intervalo: eu estive próximo de Jean Baudrillard. Tive a sorte de ter com ele encontros em cidades diferentes ou em mesas de bar, onde ele fazia cada interlocutor se sentir brilhante, sendo que brilhante mesmo era só ele. Mas também fui seu orientando, assim como de Michel Maffesoli e Edgar Morin, num pós-doutorado em sociologia sobre a miséria do jornalismo. Além disso, fui um dos seus tradutores no Brasil. Tarefa das mais gratificantes pelo exercício intelectual de alto nível. Cheguei a ajudar a produzir dois dos seus livros: Tela total, uma coletânea dos seus artigos publicados no jornal Libération, lançada no Brasil antes mesmo da existência de uma edição francesa, e $O$ Anjo de estuque - poesia e fotografia. Ambos saíram pela Sulina, editora de Porto Alegre. O casamento dos seus poemas, que já haviam sido publicados com as suas fotos foi uma novidade que muita alegria lhe deu já na sua última curva.

Ao longo dos seus 77 anos, Baudrillard experimentou de tudo um pouco sempre com a mesma intensidade. Acima de tudo, não se deixou congelar. Foi marxista, estruturalista, pós-estruturalista, patafísico, situacionista, utopista, transversal, viral e genialmente um niilista em tempo integral. Como pensador, refletiu principalmente sobre dois temas essenciais: a utopia e a radicalidade. Queria um "pensamento radical" como utopia maior. Desejava capturar algo que estivesse aquém ou além do valor de troca: o irredutível à condição de mercadoria. Extraordinário observador do mundo contemporâneo dominado pela mídia, pela publicidade e pelo consumo, ele percebeu o esgotamento 
da crítica - transformada num resmungo moralista - e passou a defender uma "teoria irônica" marcada pela capacidade de mostrar o avesso das coisas triviais. A ironia e o paradoxo foram as suas armas no combate à imbecilidade, à estupidez e à barbárie. Um exemplo: "A humanidade espera que a inteligência artificial a salve da sua estupidez natural".

Numa das suas perguntas mais clássicas, analisando todas as formas de liberação nascidas nos anos 1960 através da metáfora da orgia, ele quis saber: O que fazer depois da orgia? Depois de um surto de liberação - do corpo, da mulher, dos estudantes, da autoridade paterna - o que esperar? Baudrillard não dava respostas, não produzia manuais de utilização e não se preocupava em atender às expectativas de solução. $O$ seu papel era claro: pensar o absurdo das engrenagens sociais. Depois dele, resta a pergunta: haverá algo para fazer no pós-vida? Mas, principalmente, o que fazer depois do fim de um grande filósofo e do vazio que deixou? Talvez se convencer de que o pensamento não tem fim. Ou, como ele mesmo fez em relação à guerra do Golfo (La guerre du Golfe n'a pas eu lieu, 1991), anunciar sem hesitação: a morte de Baudrillard não aconteceu. A morte era um desaparecimento fatal. Logo...

\section{O estilo como estratégia fatal}

Ao contrário do que ocorre com a maioria dos sociólogos, Jean Baudrillard sabia escrever. Era um mestre do estilo. Mesmo que nenhuma das suas ideias fosse pertinente ainda restaria a sua forma literária, equivalente a de Nietzsche e de Cioran. A forma de Baudrillard, porém, não era vazia nem estava a serviço do narcisismo do autor. Ela reforçava um conteúdo original e impiedoso capaz de revelar as entranhas da "sociedade de consumo", caracterizada por suas mitologias publicitárias, pelas mistificações da política (que ele abordou em À l'ombre des majorités silencieuses, 1978, ou Le PC ou les paradis artificiels du politique, 1978), devorada pela indiferença dessas maiorias silenciosamente corrosivas e marcadas pelo desaparecimento, sempre em curso, do real como território de referência (Le crime parfait, 1994).

Num dos seus livros mais inspirados, Les estratégies fatales, ele advertiu: “Nous avons tout transgressé, y compris les limites de la scène et celles de la vérité" (Paris, Grasset, 1983, p. 79). No hiper-real - um dos seus conceitos mais agudos -, uma verdade mais verdadeira do que a verdade finge se impor. Então, nesse reino dos"simulacros e da simulação", só a ironia pode surtir algum efeito de desvio. Apenas a mudança da forma ainda poderia transportar algum conteúdo 
de modo a arrancar o destinatário do seu torpor conformista. Artistas plásticos e cineastas (o filme Matrix cita Simulacros e simulação) beberam fartamente nessa mudança de paradigma que considerava a realidade "uma cadela" e zombava do poder da mídia: "Les medias sont sans réponse. Mais peut-être ne sont-ils que la surface derrière laquelle les masses en profitent pour se taire?" (1983, p. 95). Para Baudrillard, a massa neutraliza a mídia por meio de uma colossal indiferença ao sentido e a todo conteúdo e toda mensagem.

Não é, portanto, estranho que os marxistas tenham ficado decepcionados e tenham passado a atacar o antigo aliado. Qualquer marxista que se respeite ainda sonha com um bom uso dos meios de comunicação e com a conscientização das massas. Mas para Baudrillard, na era dos fenômenos extremos, a crítica ideológica e moralista, fixada na ilusão do sentido e na obsessão do conteúdo, era incapaz de perceber a relevância da escrita, do ato de escrever, da forma como instância poética, ruptura irônica, argumentação alusiva, astúcia da linguagem, jogo revelador de algo que não se expressa literalmente. Em outras palavras, não há conversão possível. No seu entender, "o pensamento radical" (2004) migrou do conteúdo explícito para a forma como único elemento de desconstrução, pois, para ele, a linguagem é sempre irreal. Até mesmo quando se propõe a designar objetivamente as coisas numa função denotativa. Mesmo aí ela o faz por vias irreais, sinuosas, elípticas, irônicas.

A análise jamais pode ser frontal. A verticalidade desvia qualquer argumento do seu alvo. O caminho da interpretação com algum poder de eficácia precisa sempre ser transversal como condição para a percepção do aspecto sinuoso da existência. Nenhuma metodologia aguda estaria apta a fazer emergir a arbitrariedade do signo ou a revelar a singularidade do contingente. O pensador, nesse sentido, está obrigado a recorrer ao paroxismo, à caricatura e à reversão do sentido aparente para tentar se aproximar do mistério do objeto, esse termo que é um conceito próprio à sociedade particular surgida da revolução industrial.

\section{A necessidade do "mal"}

Pensador extremamente influente nos Estados Unidos, país onde lecionou e sobre o qual publicou um livro da melhor e mais inquietante prosa poética, Amérique (1986), Jean Baudrillard tinha horror ao puritanismo, ao moralismo, ao politicamente correto e ao imperialismo explícito ou disfarçado de processo civilizatório e democratizador. Nada o preocupava mais do que a tentativa contemporânea de expurgar todas as formas de diferença - a 
eliminação do outro, da loucura e da alteridade. Uma sociedade sem "mal", devotada a uma ideia única do "bem", parecia-Ihe uma distopia, um mundo sem zonas de sombra, inteiramente controlado, asséptico, hipócrita, fraco, inútil e estéril, incapaz de aceitar o valor e a "inteligência do mal".

$\mathrm{Na}$ verdade, Baudrillard chegou a defender um "princípio do mal". Interessava-Ihe sustentar a negatividade - tudo aquilo que está além de uma positividade de autoajuda ou de espírito carola - como um ponto de recusa, de deriva, de transgressão e de liberdade. Mergulhados nas suas ilusões positivas, os homens não perceberiam as armadilhas da domesticação, a exemplo da fatalidade estratégica de um tédio profundo, embora inusitado, produto, nas férias, da felicidade e da distração. De certa forma, ninguém quer escapar ao comodismo da sua prisão diária e produtivista. Daí a pergunta nua e crua: "Como pensar que as pessoas vão desmentir a sua vida cotidiana procurando uma alternativa?"

Bem entendido, o mal para ele era um "atrator estranho", tudo aquilo que arranca o homem da submissão e do conformismo. Depois do 11 de setembro de 2001, Baudrillard anunciou o fim da greve dos acontecimentos e nesse livro magistral que é Power inferno enunciou a mais radical hipótese em relação ao conflito entre norte-americanos e muçulmanos extremistas: os Estados Unidos teriam inveja de homens ainda capazes de morrer por uma causa, irredutíveis, não aceitando negociar nem se vender, enquanto os próprios soldados americanos partiriam para a guerra confortados por um slogan: morte zero. Como não invejar quem por idealismo se põe acima do valor mercantil?

Nada escapava das especulações de Baudrillard, nem mesmo um programa como Loft Story, o Big Brother na França. Diante da questão, por que as pessoas veem um reality-show desse tipo? Ele sugeriu a hipótese da "democracia radical". Numa democracia convencional, o preço da fama era o mérito. Loft Story instauraria a "democracia radical": todos podem ser famosos sem mérito algum, a não ser o de se tornar visíveis. Triunfo da mediocridade total na era das celebridades descartáveis e planas. Apogeu da "sociedade do espetáculo" (descrita por outro maldito, Guy Debord).

De resto, Baudrillard via a mídia, que não o fascinava como espectador, com um olhar sem complacência e divertido:

La télévision fait beaucoup parler d'elle ces temps-ci. En príncipe, elle là pour nous parler du monde et pour s'effacer devant l'événement, en bon médium qui se respecte. Mais depuis quelque temps, il semble, 
ou qu'elle ne se respecte plus, ou qu'elle se prend elle-même pour l'événement (Paris, 1997, p. 211).

\section{Paroxista (in)diferente}

Observadorincansávelearguto,JeanBaudrillard analisouamercantilização da cultura, o ocaso da utopia, a perda das ilusões revolucionárias, a derrocada do comunismo, a ascensão do consumismo, a crise das vanguardas artísticas, a "midiatização" das sociedades, o fim da sedução, a consolidação do obsceno, o fim da ideia de fim - fim das classes sociais, fim do capitalismo, fim da opressão, fim da desigualdade, fim da história -, o desenvolvimento tecnológico - virtual, clonagem etc. E ironizou a "disneificação" do mundo, "a sexualidade como doença transmissível" e o delírio como única forma de racionalidade aceitável, radical e claro emancipatória.

Foi considerado por muitos como pessimista, cínico ou apocalíptico. Numa longa entrevista para o jornalista Philippe Petit, publicada como livro em 1997, Baudrillard definiu-se como um "paroxista indiferente". Indiferente a quê? À simplificação da dicotomia otimismo/pessimismo. Mas nada indiferente em relação ao desejo de jogar, de crer na imperfeição humana como sua maior qualidade, aquilo que a máquina nunca terá - a capacidade de mentir, de blefar, de sofrer, de sonhar, de gozar. O paroxista, segundo ele, apega-se aos fenômenos extremos, mas não compartilha a crença na ilusão do fim. Baudrillard sempre quis encontrar a estratégia capaz de reinventar a vida como inutilidade absoluta e de supor um lugar de evasão inatacável:

Três vite, je me suis détaché de la sociologie des institutions, du droit, des structures sociales, de ces approches qui reposent sur l'idée d'une imagination du social, de sa transcendance. Mon objet serait plutôt une société en perte de transcendance, d'où le social, l'idée de social elle-même s'est retirée (...) ce que je reproche à la sociologie, c'est en effet son réalisme, c'est de prendre le social pour le social et de ne même pas envisager que ce soit, à un moment donné, une chance, un rêve, une utopie, une contradiction, enfin quelque chose d'autre que du social, comme si la dimension sociale était donnée (1997, p. 77-78).

Realismo limitado. Utopias ilimitadas

Não resta dúvida, Jean Baudrillard foi mesmo um extraordinário paroxista. Mas um paroxista diferente. $\mathrm{O}$ crime perfeito não acontecerá. Mas 
o crime mais que perfeito já aconteceu. Baudrillard morreu há uma década. Morte natural. Por metástase. Mas ele não desaparecerá, a não ser por multiplicação radical da sua influência irônica sobre o imaginário social em transformação permanente. Em "Le crime parfait", ele havia escrito: “La grande question philosophique était: 'Pourquoi y a-t-il quelque chose plutôt que rien?"' Aujourd'hui, na véritable question est: "Pourquoi y a-t-il rien plutôt que quelque chose?" (1995, p. 14). Agora a questão é ao mesmo tempo mais simples e incontornável: o que existe entre o fim e o nada? Para falar de Baudrillard é fundamental que uma parte sobre, que algo não seja traduzido ou não seja totalmente referenciado. Trata-se de uma homenagem ao seu princípio de irredutibilidade ao realismo castrador do social absoluto.

\section{Referências}

BAUDRILLARD, Jean. Le système des objets. Paris: Gallimard, 1968

La société de consommation. Paris: Denoël, 1970.

. Pour une critique de l'économie politique du signe. Paris: Gallimard, 1972.

. L'échange symbolique et la mort. Paris: Gallimard, 1976.

Oublier Foucault. Paris: Galilée, 1977.

L'effet Beaubourg. Paris: Galilée, 1977.

À I'ombre des majorités silencieuses. Paris: Denoël, 1978.

. Le PC ou les paradis artificiels du politique. Paris: Cahiers de l'Utopie, 1978.

De la séduction. Paris: Galilée, 1979.

Simulacres et simulation. Paris: Galilée, 1981.

. Les stratégies fatales. Paris: Grasset, 1983.

La gauche divine. Paris: Grasset, 1984.

Le miroir de la production. Paris: Galilée, 1985.

Amérique. Paris: Grasset, 1986.

L'Autre par lui même. Habilitation. Paris: Galilée, 1987. 
Cool memories I. Paris: Galilée, 1987.

Cool memories II. Paris: Galilée, 1990.

La transparece du mal. Paris: Galilée, 1990.

. La guerre du Golfe n’a pas eu lieu. Paris: Galilée, 1991.

. L’illusion de la fin. Paris: Galilée, 1992.

. Le crime parfait. Paris: Galilée, 1994.

. Fragments. Cool memories III. Paris: Galilée, 1995.

Écran total. Paris: Galilée, 1997.

Le paroxiste indifférent (com Philippe Petit). Paris: Grasset, 1997.

. Tela total: mito-ironias da era do virtual e da imagem. Porto Alegre: Sulina, 1997.

. L'échange impossible. Paris: Galilée, 1999.

Cool memories IV. Paris: Galilée, 2000.

. Mots de passe. Paris: Pauvert, 2000.

. Télémorhose. Paris: Sens \& Tonka, 2001.

. D’un fragment à l'autre (com François L'Yvonnet). Paris: Albin Michel, 2001.

. L'esprit du terrorisme. Paris: Galilée, 2002.

Power inferno. Paris: Galilée, 2002.

. La pensée radicale. Paris: Sens \& Tonka, 2004.

. Le pacte de lucidité ou l'intelligence du mal. Paris: Galilée, 2004.

. 0 anjo de estuque. Porto Alegre: Sulina, 2004.

Cool memories V. Paris: Galilée, 2005.

Oublier Artaud. Paris: Sens \& Tonka, 2005.

Le complot de l'art et compagnie. Paris: Sens \& Tonka, 2005.

À propos de l'utopie. Paris: Sens \& Tonka, 2005.

À l'ombre du millénaire ou le suspense de l'an 2000. Paris: Sens \& Tonka, 2005. 
Recebido em: 8/3/2017

Aprovado em: 9/3/2017

Endereço do autor:

Juremir Machado da Silva <juremir@pucrs.br>

Pontifícia Universidade Católica do Rio Grande do Sul (PUCRS)

Programa de Pós-Graduação em Comunicação Social (PPGCOM)

Avenida Ipiranga, 6.681 - Prédio 7

90619-900 - Porto Alegre - RS - Brasil 